\title{
7 Aufhebung von Bauleitplänen
}

Wenn ein wirksam in Kraft getretener Bauleitplan wieder aufgehoben werden soll, gelten gemäß $§ 1$ Abs. 8 BauGB ebenfalls die Vorschriften über die Aufstellung eines Bauleitplanes.

Folge ist, dass auch in diesem Fall ein eigenes Verfahren durchlaufen werden muss, welches auf die Aufhebung eines Bauleitplanes gerichtet ist. Voraussetzung für ein solches ist die Erforderlichkeit der Aufhebung des Bauleitplanes (entsprechend der Planung gemäß $§ 1$ Abs. $3 \mathrm{~S}$. 1 BauGB).

Dies ist der Fall, wenn der Bauleitplan für die städtebauliche Entwicklung und Ordnung nicht mehr erforderlich ist. Die Erforderlichkeit entfällt beispielsweise, wenn ein neuer Plan aufgestellt werden soll. Es kann keine zwei gleichzeitig geltenden Bauleitpläne für ein Gebiet geben. Üblicherweise tritt der alte Bauleitplan mit Wirksamkeit des neuen Plans außer Kraft.

Wird ein Vorhaben- und Erschließungsplan nicht durchgeführt, soll die Gemeinde diesen Plan gemäß $\S 12$ Abs. 6 S. 1 BauGB wieder aufheben.

[Anmerkung: Die Aufhebung des Vorhaben- und Erschließungsplans kann im vereinfachten Verfahren nach $\S 13$ BauGB erfolgen (§ 12 Abs. 6 S. 3 BauGB).] 